\title{
The Impact of Face Recognition Payment in the Economic
}

\author{
Mao Wei* and Dr. Valencia Pérez Luis Rodrigo \\ Department of Accountant and Administration, Universidad Autónoma de Querétaro, Mexico \\ *Corresponding author.Email:camille102326@gmail.com
}

\begin{abstract}
With the continuous development of the Internet industry, offline physical retail companies have undergone a huge technological revolution. Retail companies have broken service boundaries through evolving "new tools", better realized the collaboration of social resources, and built a huge and a humanized retail service network, and mobile payment plays a vital role in it. The rapid development of mobile payment has allowed us to gradually get rid of the dependence on cash. Even if we don't have enough cash, we can use mobile payment to complete the consumption. The innovation in the payment field includes mobile phone QR code payment, physical stores, supermarkets, pharmacies, and buses. Realizing QR code payment, just when the pattern of QR code payment is basically determined, a new payment method-face payment has appeared in our lives. Face payment can guarantee the security of the account and increase the payment efficiency, faster and more convenient.
\end{abstract}

Keywords: Face recognition payment, Face recognition, Economic, Inclusive finance.

\section{INTRODUCTION}

During the last few years the biometric has become a novel tools, however it takes several decades of evolution, Bledsoe (1960) developed a system that could classify the photos of faces by hand, using what is known as a RAND tablet, people They could use horizontal and vertical coordinates on a grid using a stylus that emitted electromagnetic pulses, this system serves to manually record the locations of the coordinates of various facial features such as the hairline, mouth or eyes. 10 years later, Goldstein Harmon and Lesk (1970) [1] added greater precision to the Manual facial recognition system by using 21 subjective markers to automatically identify faces. The Defense Advanced Research Projects Agency and the National Standards Institute launched a facial recognition technology program (1993). A database of facial images was created to include high resolution color versions. The Pinellas Sheriff's Office (2009) [2] developed a forensic database that would allow officers to access the photo files of the Department of Highway Safety and Motor Vehicles. Currently, there is a biometric personal identification system that works with mathematical data that allows knowing the features of a person's face without the need to make manual strokes. This system has been commercialized so much that
Apple included it for the first time in its iPhone $\mathrm{X}$, being the year 2017 when its technology called Face ID was announced, it was something new, many were unaware of the facial recognition process and how the features of the face could unlock the screen of your mobile.

According to the Facial recognition market-Growth, Trends, and Forecasts(2020-2025)The facial recognition market was valued at USD 4.4 billion in 2019, and it is projected to be valued at USD 10.9 billion by 2025 , registering a CAGR of $17.6 \%$ over the forecast period from 2020 to 2025. Facial recognition has been gaining traction in recent times, owing to its benefits over traditional surveillance techniques, like biometrics. Governments worldwide have been investing significant resources in the facial recognition technology, among which the United States and China are the leading adopters.

The advanced technology was well accepted by the users, it is now known as the standard for the security of various electronic devices, personnel access control systems and of course as a collection tool for businesses. In the world economy, through new technologies, it has evolved from traditional payment models, cash, checks, debit and credit cards, QR code scanning, up to facial recognition, as can be seen in each Today there are more innovations in payment models, 
more convenient, secure and faster. The technology has helped develop more advanced economics (including today's global economic), New technologies not only can help Europe and Asia country to increasing the economic and also can help Latina America Mexico's economic to get growing in the future, since it is relevant for the development of the country, it allows more equity for the population, more tools and greater security in the management of capital flows.

This article seeks to analyze and determine if facial recognition can be a tool to impact the economics in the payment process in the world and also in Mexico, promote the technological advance of payment through facial recognition to boost the economics, and identify the dimensions of this technology that has been widely accepted in the international context, so that users can benefit when making payments with facial recognition technology.

\section{DESCRIPTION OF METHODS}

In this document we invested the process of the development of the biometric face recognition in different countries and how it is impacting the economics in those countries and what is the benefit of the new technology payment

\subsection{Asia-China}

In June of 2009, Background Wisdom Eye Technology Co., Ltd. took the lead in applying facial recognition technology for qualification certification of retired people benefits in the country, which greatly facilitated people.

In August of 2014, the Chongqing Research Institute of the Chinese Academy of Sciences had developed a facial recognition payment system. In the future, you will no longer need to set multiple passwords for bank cards, just "swipe" your face.

In May of 2015, China's first independently developed facial recognition ATM passed the acceptance test. This is also the world's first ATM with facial recognition function. It will connect to banks, public security systems and other systems. You can withdraw money from your personal bank card, but it is not possible from other people's cards, even if you know the password.

Since 2014, there have many companies and instituted was developing the face recognition payment, until 2017, as smartphone manufacturers successfully launched face recognition functions, face payment began to be used on a large scale in China and penetrated into the main stages of life, such as retail and restaurants, so the industry is growing rapidly. According to data published by iiMedia Consulting in November 2019, it is estimated that China's facial payment users will exceed 760 million by 2022 . (China Economic News, 2020).

In 2020, in order to standardize innovation in the application of offline payment with face recognition (hereinafter referred to as payment by facial recognition) and prevent the security risks of payment with facial recognition, the Association for Payments and Settlement China organized and formulated the "Face Recognition Offline Payment Industry SelfDiscipline Convention (Test)" According to the data, in 2018, the number of mobile payment users in China reached 659 million, and the market size reached 277.4 billion yuan; In 2019, the number of mobile payment users exceeded 733 million, and is expected to rise to 790 million in 2020, and it will continue to grow very fast. [3]

The development and population of face payment is of great value in enhancing users' mobile payment experience, improving business efficiency, and driving the smart development of the economy and society. Industry experts believe that the rapid rise in face payment has not only changed people's lives, but also promoted the development of the related mobile payment industry chain. Especially with the accelerated application of cutting-edge technologies like 5G, AI and IT, China's face payments industry is accelerating its boom.

In China, the face payment has covered all the field, like the restaurant, shopping center, supermarket (like the flowing picture), online shopping, hotel, transport, the face recognition payment has greatly facilitated people's checkout process and shortened payment time, but payment by facial swipe still need time to cover all China, but we have to admit that the technology has increased the economic for this country.

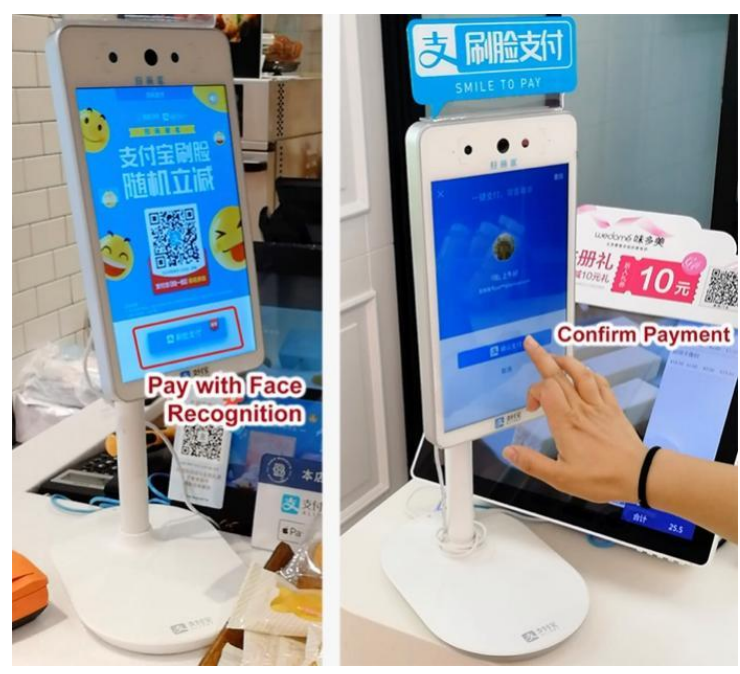

Source: Nielsen Norman Group 


\subsection{Europe}

In 2013, the Uniqul Finland company created the face recognition system with which it is possible to go shopping and make payments without carrying cash or credit cards. The use of face recognition continues to grow in Spain, in October 2019, Madrid published the news of the pilot project that was going to be implemented in several buses in Madrid to pay through face recognition and one of the places where it is used is in the well-known South Station of Madrid. BBVA is also using the face recognition payment system in Ciudad BBVA for employees to use it in its restaurant. This technology that they have developed through the Veridas company has been called Selfie \& Go as seen in the following photo.

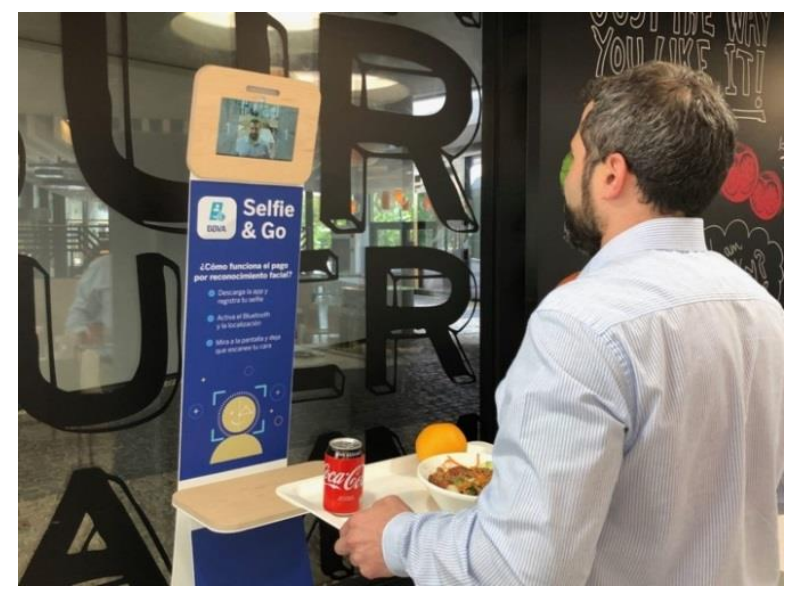

Source:BBVA

The 'Selfie \& Go' system has been developed jointly with Sodexo Iberia, the Group's restaurant partner. [6] The initiative is part of a pioneering project in the world with the aim of introducing this type of innovative payment experiences in restaurants and cafes, and later in other sectors. "This is a fantastic solution that perfectly meets customer experience needs. It's fast, it's safe and it's going to drastically change the way people pay for products and services, so that they do it, literally, for their faces", explains Guillermo Sánchez, who leads the project of the Global Payments team of BBVA. (Finance, 2018) Also, payment technology through facial recognition has been implemented in the retail sector, for example, the Viena restaurant on Avd. Diagonal, 405 in Barcelona that allows facial recognition payment and the Nestle Market store in Esplugues de ILOBREGAT (Barcelona) the user you can pay with a "selfie". The main advantage of facial recognition technology in retail is that it allows immediate payment, without going through the box and without the need for personnel. All this through various applications.
Safe and efficient payment systems are essential to the working of financial markets and the economic more generally.

Taking advantage of technological developments, a number of new payment initiation methods have emerged, using the internet, mobile networks and other information and communication technologies. these offer efficient means of electronically initiating and confirming payments that meet consumer's needs.

\subsection{Mexico}

Mexico is one of the countries with the highest incidence of cyber fraud in identity theft, which has led both authorities and banking institutions to take measures to help users protect their personal data. In this context, BBVA México has developed face recognition as a tool so that only customers can use their digital banking through the BBVA México 'app'.

The BBVA Mexico 'app' will ask the customer to register the face fingerprint through the camera of their mobile device to offer this new level of protection in the use of digital banking. Activating face recognition is vital for safeguarding bank details, as it is a way to ensure that no one else can enter and use the application. Some sensitive data includes card numbers, dynamic CVV, account statements, balances, and so on. Since last March and by provision of the National Banking and Securities Commission (CNBV), financial institutions are obliged to begin the implementation of mechanisms to verify the identity of their clients in order to reduce the incidence of cyber fraud by means of identity theft. (BBVA MEXICO, 2020) BBVA Mexico is the first bank that is using face recognition, it gives a signal that Mexico is trying to implement and use the new technology, to protect users and improve their experience when making purchases and sales and also trying to use the new technology to improve the economic in the country. [4]

In the investigation of the situation of the microbusiness in Mexico during the COVID-19, and how the face recognition payment can be used as a tools to promote the micro-business in this country, at the end arrive the goal to increase the Mexico economic. [5]The micro-business situation, during the pandemic in Mexico, its in a difficult economic situation, many companies or shops are bankrupt and people have lost their jobs, but we have seen that the pandemic also provides a window of opportunity, it is raising many companies and businesses such as Uber eats, Rappi, and different companies that offer services through applications, there are restaurants that implemented delivery to your home, and financial institutions has published many different products to give more access to financial or bank credits in order to help people improve their sistuations and businesses during this 
pandemic, it is also a good time to adapt new technology such as payment of face recognition in Mexico, to gether more income for micro-businesses, reactivating the economy and avoiding contagion between people avoiding payments with cash or bank cards.

\section{THE BENEFIT OF FACE RECOGNITION PAYMENT}

With the development of the technology, nowadays, more and more people are get used to use the phone to make the payment, like in China have WeChat pay, Ali pay, and apple pay and Android pay, when they are doing the payment, just need the face recognition then get paid within 15 seconds.

The value of the currency and the methods of the payment has been changed in the whole history, with the development of the internet, AI, and big data, we already accept the changes from pay cash to digital payment, online bank and un-touch payment, all those changes are a signal that the face recognition payment will be a trend in the future.

Here we are showing a picture from Nielsen Norman Group, between the different payment methods, and we can know the face recognition is more faster than any other payment methods.

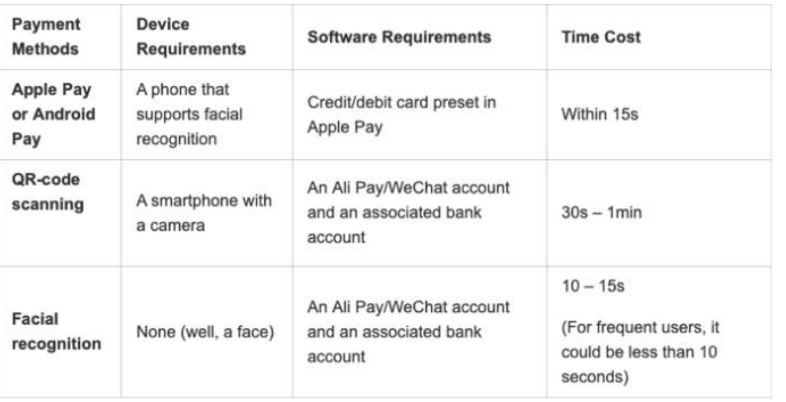

Source: Nielsen Norman Group

The face recognition payment first make your money more security and make the payment for efficiency and more quick, its saving your time, and give the user have a better experience of the life. [7]

Also with the new payment face recognition, people can make the payment as show in the picture that they can do the payment anytime, anywhere like you can do it in your home or in the shop o shopping mall even if you are in other country and anyway, like you can do it through your phone, your computer also in the store.

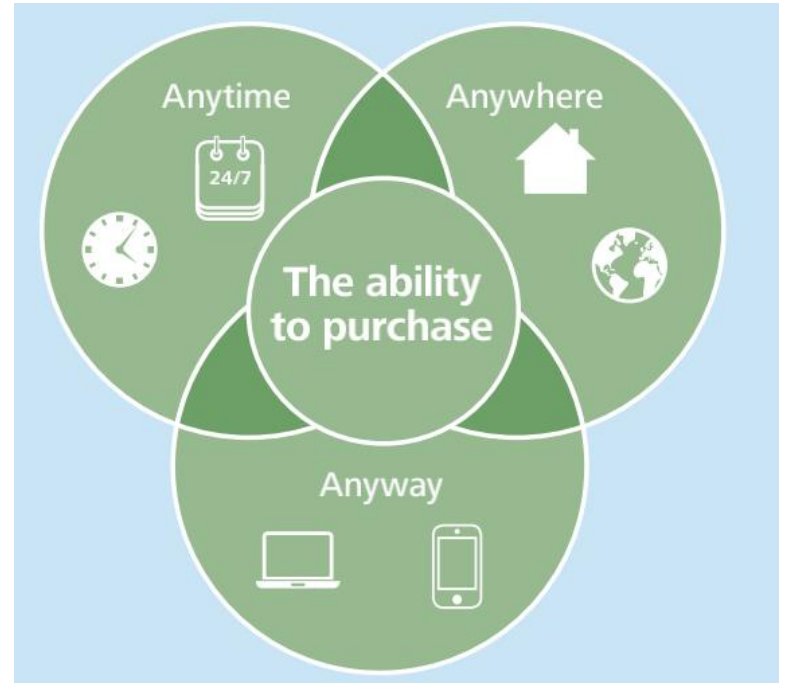

Source: The economic impact of online payment breaking barriers across Europe

\section{CONCLUSION}

The biometric technology has been fully applied in different industrial, the payment methods from the finger recognition to face recognition, it is a breakthrough and innovations in the payment technology industry.

It also ensures the information security and financial security of the final customers. This technology has been widely used in various stores and supermarkets in China, Europe, Colombia and other countries, makes the payment process faster, more convenient and for sure the face recognition payment will become a payment trend in the future in all over the world. As a way to impact the economic in the world.

In September 2016, the G20 heads of state and government endorsed the High-Level Principles of Digital Financial Inclusion (HLPs), recognizing the capacity of digital to help people get access to financial services. Certainly, countries with dedicated digital policies and infrastructure have seen faster progress. [8]

In the same time all the country also need to establish the right incentives to encourage the user and the merchants to using the face recognition payment, this way can reduce the cost of digital payments and make the payment get more easier and faster. Like in China, Chinese mobile payment leaders Alipay and WeChat Pay are engaged in an ongoing battle to attract users to use the face recognition payment.

In the end, the face recognition payment is becoming a trends of payment in the future and it is impacting the economies in many countries. 


\section{RECOMMENDATIONS}

China is one of the major consumers and exporters of the facial recognition technology, as the law and enforcement, along with various government bodies in the country, adopted surveillance technologies. [9] As we know China and USA are the main country of the face recognition technology, and we suggest that China can hold the chance to export this technology to more country to help those third party countries can instar the technology and to help them to easy their life and in the end to impact the economic.

There is an old saying in China “任何 事物 都有 两 面性 (Rènhé shìwù dōu yǒu liăngmiànxìng)" which means "everything has two faces". Last year 2020, the COVID-19 has affected the global economic, but also raised up many new industries. According to the economic situation of Mexico, the following suggestions are made, hoping to stimulate the economic development of Mexico: First, the government departments, the Ministry of Economy, the Ministry of Finance and others involved, should formulate more plans and provide government funds to the poor with supplemental monthly funds to help them solve their food and clothing problems. Second, banking departments and financial companies should provide more financial products, open mobile banking applications, so that more users can use the mobile banking application to manage money, and at the same time authorized mobile phone users they can sign up for face recognition in the mobile banking app. Face recognition transfers, payments, purchases, etc., while reducing credit card interest and extending payment time. Third, install face recognition payment devices in shopping malls, shops, and micro-businesses, so that customers can use this biometric technology. Fourth, improve the telecommunications infrastructure so that access to the network is seamless. Even during the period of the virus, many people can acquire new knowledge through the Internet, because knowledge is also a means to reduce poverty.

\section{AUTHORS' CONTRIBUTIONS}

Mao Wei, student of Master Degree Master of Technology from the Universidad Autonoma of Queretaro, Mexico. She has published 2 articles and 1 magazine. She has worked 4 years in the international business. She was a Chinese teacher in the university of Michoacan de San Nicolas in Morelia, Mexico.

Dr. Valencia Pérez Luis Rodrigo. Graduated as Industrial Engineer (ITESM), Master in Information Systems (ITESM) and Doctor in Technology and Innovation Management (UAQ). He was CEO of four companies in the central region of Mexico; clothing, social networks (marketing) and metalworking automotive companies. He is the author of two books and the co-author of seven more books. He is a worldwide speaker and columnist of numerous articles on optimization of processes and functions in SMEs, is a research professor and Academic Coordinator of master's programs at the Autonomous University of Querétaro, as well as an industrial advisor in cloud computing, technology management and Industrial engineering.

\section{ACKNOWLEDGMENTS}

First of all, we thanks to my parents that supporting me to study the master degree Management of Technology in Mexico, and then would like to thanks the teacher Minerva and Dr. Alberto Ruiz (University of Michoacan San Nicolas) they helped me a lot, and then would like to thanks Dr. Valencia Pérez Luis Rodrigo (University of Autonoma Queretaro), he helped to review my article and give me the suggestions how to correct it and also want to thanks my friends Salvador who is journalist he helped me with the grammar of the sentence to be more professional, in the end, would like to thanks Consejo Nacional of Ciencia y Tecnologia (CONACyT) with the support of the scholarship. And thanks all my friends in my live, thanks very much.

\section{REFERENCES}

[1] Joseph N. Pato, L. (2010). Biometric Recognition. Washington,D.C: NATIONAL RESEARCH COUNCIL

[2] Tapiador M. (2005). Tecnologias Biometricas Aplicadas a la Seguridad.Espana: Rama.

[3] Zhong, T., (2020). Resultados contables preliminares del producto interior bruto (PIB) en el primer trimestre de 2020. Dirección de internet: http://www.gov.cn/xinwen/202004/18/content_5503803.htm

[4] BBC News Mundo, 2020. "La economía y el coronavirus: los negocios ganadores y los sorpresivos perdedores durante la pandemia", recuperado mayo 14,2020. Dirección de internet: https://www.bbc.com/mundo/noticias-52647431

[5] Blancas, A. 2020. "Impacto financiero por COVID19 en las empresas mexicanas" https://blog.sodexo.com.mx/blog/impactofinanciero-covid-en-empresas-mexicanas

[6] Feifei Liu, May 10, 2020. "Making Cutting-Edge Technology Approchable: A case study of facialrecognition payment in china". Direction of internet: https://www.nngroup.com/articles/face-recognitionpay/

[7] BBVA. Jun 2018. "BBVA lanza un sistema de pagos por reconocimiento facial". Direction of 
internet: https://www.bbva.com/es/bbva-lanzasistema-pagos-reconocimiento-facial/

[8] Markus Massi, Godfrey Sullivan, Michael Straub and Mohammad Khan, May 2019. "How cashless payments help economies grow". Direction of internet: https://www.bcg.com/publications/2019/cashless-

payments-help-economies-grow

[9] Reportlinker, May 2020. Facial recognition marketgrowth, trends, and forecast(2020-2025).Direction of the internet: https://www.prnewswire.com/newsreleases/facial-recognition-market---growth-trendsand-forecast-2020---2025-301055388.html 